\title{
Research on Comprehensive Performance Evaluation of Cultivation Machinery for Tea Garden
}

\author{
Xiao Hongru, Mei Song*, Song Zhiyu, Ding Wenqin and Han Yu \\ Nanjing Research Institute for Agricultural Mechanization, Ministry of Agriculture, 210014 Nanjing, Peoples, Republic of China
}

Received: 24 Sep. 2013, Revised: 22 Dec. 2013, Accepted: 23 Dec. 2013

Published online: 1 Sep. 2014

\begin{abstract}
Tea garden tiller is one of the most widely used in China, which is indispensable equipment for soil tilling in tea garden. The performance of tea garden tiller is always focused on when being used. Meanwhile, researches on evaluating the performance of tea garden tiller have been rarely reported. So it is of importance to find a methodology to evaluate tiller's performance. In this paper, the important indexes of tiller performances are presented firstly, including fuel consumption, cultivation time, cultivation depth, cultivation width and soil crushing ratio. Then these indexes for eight different types of cultivation machineries from home and abroad are experimented and detected. Thirdly, rough sets and radar chart are utilized for performance evaluation of cultivation machineries, where rough set theory is to determine the weight of performance index and radar chart for performance analysis. Finally, performance of cultivation machinery is analyzed based on radar chart, which can provide the convenience and proof of optimal cultivation machinery selection for farmers. The results of radar chart analysis show that operational performance of KAMA B is the best and Little White Dragon B stand the second place. In addition, from the performance analysis, the deficiencies of service cultivation machinery can be found and the improvements can be suggested.
\end{abstract}

Keywords: tea garden tiller; performance evaluation; rough set theory; radar chart

\section{Introduction}

Tea garden cultivation is an important part in tea garden management, which is advantageously functioned by weeds cleaning, soil loosing, soil maturation promotion and so on[1]. Currently, with the increasing of labor transfer and tea garden management costs, tea garden machinery need to conform with tea garden management tendency. There are various cultivation machineries available, some of which have been under research for performance improvement by experts at home and abroad. However, little is about the performance evaluation,[2]. So it is of importance to research the performance evaluation for tea garden tiller. The researches about performance evaluation have been carried out in many fields, such as industry, agriculture, military and so on. The most commonly applied methods for performance evaluation include rough set theory and fuzzy optimization model. Ye wei et al. utilized rough set to reduce the evaluation index for crane performance[3]. Tong Y.F. proposed energy-saving evaluation architecture for lifting machinery from the view of metal structure, transmission mechanism and electronic control[4]. In addition, some intelligent algorithms, such as GA, BP neural network and so on are used to model and solute the performance optimal selection[5]. In this paper, rough set theory and radar chart model will be adopted to research the performance evaluation of tea garden tiller. Radar chart model arises from phylogenetic analysis of TRIZ[6]. Technical evolution model and route is a hot research of TRIZ -technical evolution theory. According to statistics, about 20 kinds of typical evolutionary modes and 350 evolutionary routes have been developed by academic researchers, the most renowned of which are 6 kinds of evolutionary modes proposed by Fey V. and Rivin V, 10 by Zlotin B. and Zusman A, and 11 by Mann $\mathrm{D}$ characterized by deep, systematic and structural research. In this paper,a multi-view drawing techniques from a system performance model - the radar map based on technology Evolutionary Potential which is proposed by Mann $\mathrm{D}$ is adopted to analyze comprehensive performance of tea garden tiller. The present work was carried out in order to obtain the result of performance of cultivation machinery, which can provide the convenience and proof of optimal cultivation machinery selection for

\footnotetext{
* Corresponding author e-mail: meisong100@163.com.
} 
farmers. In the next section, the experiment for eight types of tea garden tiller was carried out in Yunnan large leaf tea area and its results were achieved. In Section 3, rough sets and radar chart model are introduced into performance evaluation of cultivation machineries, where rough set theory is utilized to determine the weight of performance index and radar chart is for performance analysis. In Section 4,according to the results of experiment summarized in Section 2, radar charts for eight types of tea garden tiller were drew when the weight of performance index was calculated by means of rough set theory. And the performance of eight machineries was analyzed based on radar charts followed. Finally, research conclusions are summarized.

\section{Test \& its results}

(1)Determination of experiment subjects

Eight different types of cultivation machineries for tea garden from home and abroad are selected for testing, whose technical parameters are as listed in Table 1. After brain storming of field experts, fuel consumption, cultivation efficiency, tillage depth, tillage width and soil crushing rate are selected as performance index of test.

(2)Test[7]

On August 17/2013, field tests of cultivation machineries are carried out in Yunnan large leaf tea area.

1.Brief introduction of test field

The test field covers six acres and relative criteria are listed in Table. 2

\section{Test means}

Aiming at the test index, the test can be carried out as follows: 1) Fuel consumptions detection Get 1L petrol (diesel) by cylinder into cultivation machinery before test and the rest after tillage by cylinder, then petrol (diesel) consumptions of per test can be obtained. 2) Cultivation efficiency detection Record the tillage time and area (unit/ acre) and the efficiency (acre/s) can be obtained. 3) Tillage depth detection Three tillage points randomly are selected to measure the tillage depth after each tillage. 3) Tillage width detect Three tillage points randomly are selected to measure tillage width after each tillage. 5) Soil crushing rate detection Three tillage points randomly are selected after each tillage, centering which, clods in whole tillage layer of $0.33 \mathrm{~m} 0.33 \mathrm{~m}$ area are detected. The soil crushing rate is the percentage the weight of clods, whose longest edge is shorter than $5 \mathrm{~cm}$, play of the total mass.

3.The results

The detection results can be shown as in Table .3 .

Next, the test results above will be utilized for weights solution of index to optimization based on rough set.

\section{Rough set theory and determination of weight method}

\section{(1)Rough set[8]}

Let $U$ be an uncertain domain associated with a equivalence relation $[x]_{R}$ is the equivalence relation on the generated-equivalence class and $\mathrm{X}$ is a subset of the $\mathrm{U}$. There are:

$$
\begin{gathered}
R_{-}(X)=\left\{x \in U \mid[x]_{R} \subseteq X\right\} \\
R^{-}(X)=\left\{x \in U \mid[x]_{R} \subseteq X \neq \varphi\right\}
\end{gathered}
$$

(2)Information system [3]

Let $S=\{U, A, V, f\}$ be an information system, where $\mathrm{U}$ denotes the discussed domain and $(A=C \cup D)$ denotes the set properties. Subset of $C$ and D respectively refer to sets of condition attributes and decision attributes sets. $V=\bigcup_{a \in A} V_{a}$ is the set attribute value and f: $U \times A \rightarrow V$ is an information function. Set each attribute subsets as B and define $\operatorname{IND}(B)$ as an indiscernibility binary equivalence relation, where $\operatorname{IND}(B)=\bigcap_{b \in B} \operatorname{IND}(\{b\})$. (3)Determination of the importance of attributes[9] Definition 1:Let $\mathrm{K}=(\mathrm{U}, \mathrm{R})$ be a knowledge base $(r \in R$ as an equivalence relation ) and $\mathrm{GD}(\mathrm{R})$ is granularity from knowledge $r \in R$ :

$$
G D(r)=\frac{|r|}{\left|U^{2}\right|}=\frac{|R|}{\left|U^{2}\right|}
$$

Definition 2 : Let $K=(U, r)$ be a knowledge base $(r \in R$ as an equivalence relation) and $\operatorname{Dis}(r)$ is definition from knowledge $r \in R$ :

$$
\operatorname{Dis}(r)=1-G D(r)
$$

Set $S=\{U, A, V, f\}$ is an information system, $A=C \cup D$ ,$X \subseteq C$ is a subset of attributes, $x \in X$ is a attribute,Considering the importance of $\mathrm{x}$ to $\mathrm{X}$, that is the improvement degree of definition after adding attribute $\mathrm{X}$ to $\mathrm{X}$, the degree of improvement is greater, attribute $\mathrm{x}$ is more important for $\mathrm{X}$.

Definition 3 Set as a subset of attributes, as a attribute, if attribute importance degree of $\mathrm{x}$ to $\mathrm{X}$ is, its definition:

$$
\operatorname{Sig}_{X}(x)=1-\frac{|X \cup\{x\}|}{|X|}
$$

Among them: $|X|$ is taken as $|I N D(X)|$, $\operatorname{Set} \frac{U}{|I N D(X)|}=\frac{U}{X}=\left\{X_{1}, X_{2}, \cdots, X_{n}\right\} \quad$,then $|X|=|\operatorname{IND}(X)|=\sum_{i=1}^{n}\left|X_{i}\right|^{2}$

Comparing the method introduced above and the subjectively determined weight, the method is based on test data and scientific calculations, mining the test data to find an intrinsic relation in the importance of index data, therefore, it is more objective and can improve the accuracy of evaluation results.

(4)Synthetic weights method [10] 
Table 1: Technical parameters of cultivation machineries

\begin{tabular}{|c|c|c|c|c|}
\hline Tiller & $\begin{array}{c}\text { Little White Dragon } \\
\text { Tiller }\end{array}$ & KAMA Tiller & Honda Tiller & $\begin{array}{c}\text { Capterpillar type } \\
\text { plowed Tiller }\end{array}$ \\
\hline Brand & Little White Dragon & KAMA & Honda & TKK \\
\hline Manufacturer & $\begin{array}{c}\text { Luoyang Dragon Horse } \\
\text { Machinery Co,.LTD }\end{array}$ & $\begin{array}{c}\text { Wuxi worldbest kama } \\
\text { power co., LTD }\end{array}$ & $\begin{array}{c}\text { Jialing - Honda } \\
\text { Engine Co. Ltd. }\end{array}$ & $\begin{array}{c}\text { Hebei TKK Machinery } \\
\text { Manufacturing Co., Ltd. }\end{array}$ \\
\hline Type & 1 WG3.3A,B & KW3CG-50(A,B $)$ & FJ500(A,B) & 3 ZFL-40(A,B) \\
\hline Weight $(\mathrm{kg})$ & 45 & 105 & 60 & 78 \\
\hline Equipment size $(\mathrm{mm})$ & $1200 * 780 * 900$ & $1150 * 600 * 1050$ & $1395 * 900 * 1080$ & $1250 * 550 * 800$ \\
\hline Standard tillage depth $(\mathrm{cm})$ & 1015 & 715 & 10 & 50100 \\
\hline Standard tillage width $(\mathrm{cm})$ & 65 & 3050 & 90 & 3050 \\
\hline $\begin{array}{c}\text { Maximum output power } \\
\text { of the engine }(\mathrm{kw})\end{array}$ & 3.3 & 2.5 & 3.05 & 3.5 \\
\hline Fuel tank capacity $(\mathrm{L})$ & - & 2.5 & 2.4 & 6 \\
\hline Fuel & gasoline & diesel & gasoline & gasoline \\
\hline
\end{tabular}

Table 2: Relative criteria of test field

\begin{tabular}{|c|c|c|c|c|c|c|}
\hline Criteria & $\begin{array}{c}\text { Tree height } \\
(\mathrm{cm})\end{array}$ & $\begin{array}{c}\text { Tree amplitude } \\
(\mathrm{cm})\end{array}$ & $\begin{array}{c}\text { Tree width } \\
(\mathrm{cm})\end{array}$ & Soil type & Soil moisture & Breed \\
\hline Yunnan Pu'er tea garden & 82.4 & 165.6 & 215.4 & Red loam & $13.29 \%$ & Yunkang No.10 \\
\hline
\end{tabular}

Table 3: Test results for all indexes

\begin{tabular}{|c|c|c|c|c|c|}
\hline Machinery & $\begin{array}{c}\text { Fuel consumption } \\
(\text { L/acre })\end{array}$ & $\begin{array}{c}\text { Cultivation efficiency } \\
(\mathrm{s} / \text { acre })\end{array}$ & $\begin{array}{c}\text { Tillage depth } \\
(\mathrm{cm})\end{array}$ & $\begin{array}{c}\text { Tillage width } \\
(\mathrm{cm})\end{array}$ & $\begin{array}{c}\text { Soil crushing rate } \\
(\%)\end{array}$ \\
\hline L.W.D A & 0.25 & 1075.01 & 12.33 & 64.78 & 62.77 \\
\hline L.W.D.B & 0.25 & 986.87 & 14.11 & 72.89 & 82.19 \\
\hline KAMA A & 0.16 & 1264.05 & 14.11 & 43.22 & 57.44 \\
\hline KAMA B & 0.16 & 1220.19 & 16.11 & 64.78 & 82.98 \\
\hline Honda A & 0.35 & 1269.91 & 9.44 & 69.67 & 61.00 \\
\hline Honda B & 0.35 & 1201.94 & 11.89 & 73.89 & 68.17 \\
\hline TKK A & 0.31 & 860.22 & 9.11 & 26.44 & 89.07 \\
\hline TKK B & 0.31 & 982.38 & 9.89 & 31.56 & 82.12 \\
\hline
\end{tabular}

In information system of $S=(U, A, V, f)$, each attribute value of which has different influence on decision attribute in the condition attributes set of $C \in A$. Therefore, their weights should be determined. In this article, the final weight I are composed by subjective and objective components, the objective of which is solved by the above calculation method and denoted by $\mathrm{P}$ and the subjective one is based on expert's experience and denoted by Q:

$$
I=\alpha Q+(1-\alpha) P \quad(0 \leq \alpha \leq 1)
$$

Among them: is called the experience factor, $0 \leq \alpha \leq 1$, which reflects decision maker's preference degree between objective weight and subjective weight in the decision making process, if is larger,the decision makers pay more attention to the experience of experts; On the contrary, they pay more attention to objective weigh. Two limits in formula 2 are objective weight and subjective weight.

\section{Radar chart modeling}

According to the test index, the radar chart model is established as shown in Figure1, which can be illustrated as in Table.4. Fig. 1 Radar chart for performance evaluation of tea garden cultivation machinery

According to Table 4, the paper solves five above indexes by the synthetic weights method based on rough set theory, and $\sum_{j=1}^{10} i_{j}=1$. The five indexes can be divided into two categories of cost index and effectiveness index. The former value is the lower the better, and the latter is the higher the better; Fuel consumption and cultivation time are cost indexes, the others are effectiveness indexes. As in Figure1, there are five axes representing the five indexes around the circle respectively, and each axis is divided into three parts. Where the index is marked in the axis is determined by its grade, which will be discussed in detail in the next section. The angle between the adjacent axis is $\alpha\left(\alpha=360^{\circ} \times i\right.$, where denotes the index weight $)$. 
Table 4: Weight of each index

\begin{tabular}{|c|c|c|c|c|c|}
\hline Number & 1 & 2 & 3 & 4 & 5 \\
\hline Index(i) & Fuel consumption & Cultivation efficiency & Tillage depth & Tillage width & Soil crushing rate \\
\hline Weights & $c_{1}$ & $c_{2}$ & $c_{3}$ & $c_{4}$ & $c_{5}$ \\
\hline
\end{tabular}

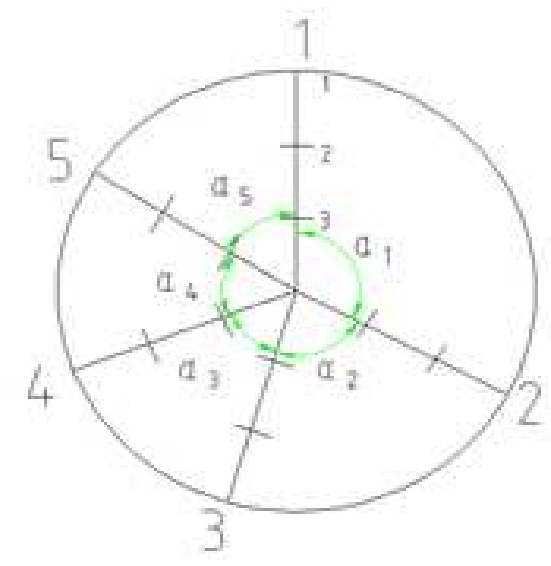

Fig. 1: Radar chart for performance evaluation of tea garden cultivation machinery.

Table 5: The comprehensive performance evaluation parameters

\begin{tabular}{|c|c|c|}
\hline Target layer & Evaluation parameters & Mark \\
\hline Comprehensive & Fuel consumption(L/acre) & $c_{1}$ \\
performance & Cultivation efficiency(s/acre) & $c_{2}$ \\
evaluation & Tillage depth $(\mathrm{cm})$ & $c_{3}$ \\
parameters & Tillage width $(\mathrm{cm})$ & $c_{4}$ \\
system & Soil crushing rate $(\%)$ & $c_{5}$ \\
\hline
\end{tabular}

Then, the radar chart can be determined and utilized for further performance analysis. In addition, this paper utilizes this method to determine the radar chart model of all tillers and evaluate the tea farm tillers' performance.

\section{Performance analysis for tea garden tiller}

(1)Determination of index weight [11]

The comprehensive performance evaluation parameters system is established as shown in Table.5.

According to Table 4, 5 and test results, the performance evaluation information system for tea garden tiller is established as in Table. 6

In order to evaluate the comprehensive operational performance of tea garden tillers, each index should be divided into three grades, of which 1 denotes "excellent", 2 denotes "good" and 3 denotes "poor." Relevant historical data for literature and indicators premised on the design requirements of tiller are consulted. Besides, expert opinions are also adopted to determine criteria for the classification which can be shown in Table.7.
Table 6: Comprehensive performance evaluation information system

\begin{tabular}{|c|c|c|c|c|c|}
\hline $\mathrm{U}$ & $c_{1}$ & $c_{2}$ & $c_{3}$ & $c_{4}$ & $c_{5}$ \\
\hline$u_{1}$ & 0.25 & 1075.01 & 12.33 & 64.78 & 62.77 \\
\hline$u_{2}$ & 0.25 & 1086.87 & 14.11 & 72.89 & 82.19 \\
\hline$u_{3}$ & 0.16 & 1264.05 & 14.11 & 43.22 & 57.44 \\
\hline$u_{4}$ & 0.16 & 1220.19 & 16.11 & 64.78 & 82.98 \\
\hline$u_{5}$ & 0.35 & 1269.91 & 10.44 & 69.67 & 61 \\
\hline$u_{6}$ & 0.35 & 1201.94 & 11.89 & 73.89 & 68.17 \\
\hline$u_{7}$ & 0.31 & 860.22 & 9.11 & 26.44 & 89.07 \\
\hline$u_{8}$ & 0.31 & 982.38 & 9.89 & 31.56 & 82.12 \\
\hline
\end{tabular}

Table 8: Comprehensive performance evaluation information system for tiller

\begin{tabular}{|c|c|c|c|c|c|}
\hline $\mathrm{C}$ & $c_{1}$ & $c_{2}$ & $c_{3}$ & $c_{4}$ & $c_{5}$ \\
\hline$u_{1}$ & 2 & 2 & 2 & 1 & 2 \\
\hline$u_{2}$ & 2 & 2 & 1 & 1 & 1 \\
\hline$u_{3}$ & 1 & 3 & 1 & 2 & 3 \\
\hline$u_{4}$ & 1 & 2 & 1 & 1 & 1 \\
\hline$u_{5}$ & 3 & 3 & 2 & 1 & 2 \\
\hline$u_{6}$ & 3 & 2 & 2 & 1 & 2 \\
\hline$u_{7}$ & 3 & 1 & 3 & 3 & 1 \\
\hline$u_{8}$ & 3 & 1 & 3 & 3 & 1 \\
\hline
\end{tabular}

Comparing Table.6 and Table.7, information system for tiller can be transferred as Table.8.

Index weight is calculated as follows: $X_{1}=\left\{c_{2}, c_{3}, c_{4}, c_{5}\right\}$ Within, X1 denotes the importance of attribute $c_{1}$; Meanwhile, $\operatorname{card}\left(u_{1}\right)=\cdots=\operatorname{card}\left(u_{8}\right)=1$. $U / I N D\left(X_{1}\right)=\left\{\left\{u_{1}, u_{6}\right\},\left\{u_{2}, u_{4}\right\},\left\{u_{7}, u_{8}\right\},\left\{u_{3}, u_{5}\right\}\right\}$, so, $\left|X_{1}\right|=2^{2}+2^{2}+2^{2}+2^{2}=16$, AndU $/ \operatorname{IND}(X)=$ $\left\{\left\{u_{1}\right\},\left\{u_{2}\right\},\left\{u_{3}\right\},\left\{u_{4}\right\},\left\{u_{5}\right\},\left\{u_{6}\right\},\left\{u_{7}\right\},\left\{u_{8}\right\}\right\} ;$ so, $\left|X_{1} \cup\left\{c_{1}\right\}\right|=$ $1^{2}+1^{2}+1^{2}+1^{2}+1^{2}+1^{2}+1^{2}+1^{2}=8 ; \operatorname{so}^{2} \operatorname{Sig}_{X_{1}}\left(c_{1}\right)=$ $1-\frac{\left|X_{1} \cup\left\{c_{1}\right\}\right|}{\left|X_{1}\right|}=1-\frac{8}{16}=0.5 ;$ Likely, $\operatorname{Sig}_{X_{2}}\left(c_{2}\right)=$ $1 / 3, \operatorname{Sig}_{X_{3}}\left(c_{3}\right)=0.2, \operatorname{Sig}_{X_{4}}\left(c_{4}\right)=0.2, \operatorname{Sig}_{X_{5}}\left(c_{5}\right)=0.2$ Subjective weights can be determined by experts as: $Q_{1}=0.3, Q_{2}=0.2, Q_{3}=0.15, Q_{4}=0.15, Q_{5}=0.2$ Meanwhile, objective weights are also calculated as follows: $\quad P_{c 1}=\frac{0.5}{0.5+1 / 3+0.2+0.2+0.2}=\frac{15}{43}, P_{c 2}=$ $\frac{1 / 3}{2+0.2+0.2+0.2}=\frac{10}{43}, P_{c 3}=P_{c 4}=P_{c 5}=$ $\frac{1 / 3}{0.5+1 / 3+0.2+0.2+0.2}=\frac{0.2}{43}, P_{c 3}=P_{c 4}=P_{c 5}=$
$\frac{0.5+1 / 3+0.2+0.2+0.2}{0.5}$ According formula (2), due to that objective weight is of more importance than subjective one, set experience factor $\alpha=0.4$, and then synthetic weights of each attribute index can be solved as follows: $I\left(c_{1}\right)=0.4 \times 0.3+0.6 \times \frac{15}{43} \approx 0.329, I\left(c_{1}\right)=$ 
Table 7: Index evaluation standard

\begin{tabular}{|c|c|c|c|c|c|}
\hline Rank & $\begin{array}{c}\text { Fuel consumption } \\
\text { (L/acre) }\end{array}$ & $\begin{array}{c}\text { Cultivation } \\
\text { time(s/acre) }\end{array}$ & $\begin{array}{c}\text { Cultivation } \\
\text { depth }(\mathrm{cm})\end{array}$ & $\begin{array}{c}\text { Cultivation } \\
\text { width }(\mathrm{cm})\end{array}$ & $\begin{array}{c}\text { Soil crushing } \\
\text { rate }(\%)\end{array}$ \\
\hline 1 & {$[0,0.2]$} & {$[0,1000]$} & $>14$ & $(50,80]$ & $>80$ \\
\hline 2 & $(0.2,0.3]$ & $(1000,1250]$ & $(10,14]$ & $(35,50]$ & $(60,80]$ \\
\hline 3 & $>0.3$ & $>1250$ & {$[0,10]$} & {$[0,35]$} & {$[0,60]$} \\
\hline
\end{tabular}

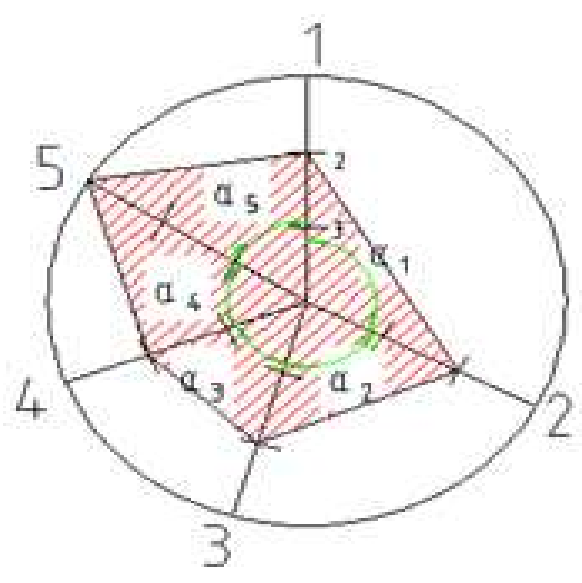

Fig. 2: Performance evaluation radar chart for Little White Dragon A.

$0.4 \times 0.2+0.6 \times \frac{10}{43} \approx 0.219, I\left(c_{3}\right)=I\left(c_{4}\right)=0.4 \times 0.15+$ $0.6 \times \frac{6}{43} \approx 0.144, I\left(c_{5}\right)=0.4 \times 0.2+0.6 \times \frac{6}{43} \approx 0.164$. (2)Radar chart modeling According to the above calculation results, the angle between the adjacent axis determined as well as the position where each index is marked in the axis. Therefore, $\alpha$ can be calculated based on the formula of $\alpha=360^{\circ} \times i$ as follows:

$$
\alpha_{1}=0.329 \times 360^{\circ}=118^{\circ}, \alpha_{2}=0.219 \times 360^{\circ}=79^{\circ}
$$

Likely, $\alpha_{3}=\alpha_{4}=52^{\circ}, \alpha_{5}=59^{\circ}$ Therefore, the radar chart for the eight evaluation objects can be obtained as follows.

\section{Conclusions}

1) According to the principle, that larger the area marked in red covers, better performance for deep ploughing the machinery has, it can be concluded that, operational performance of KAMA B is the best and then Little White Dragon B stand the second place. The two models for TKK have the same deep plow effect which is worser than others; Two kinds of models for Little White Dragon and Honda have similar cultivating effect and performance. 2) Performance of KAMA B is evaluated as the best. However, its cultivation efficiency is lower than others. Therefore, improvements of machinerys weight

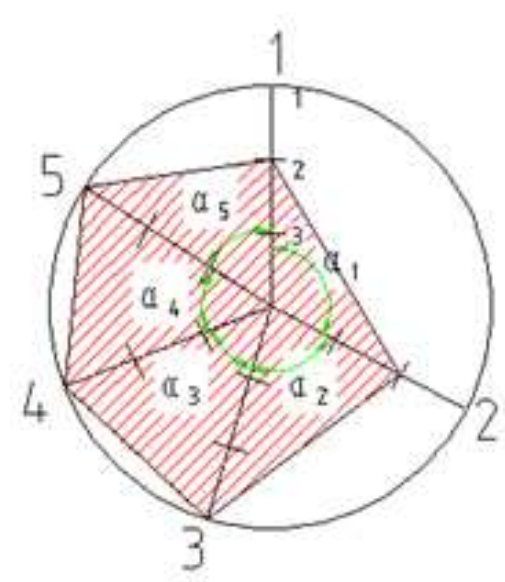

Fig. 3: Performance evaluation radar chart for Little White Dragon model two.

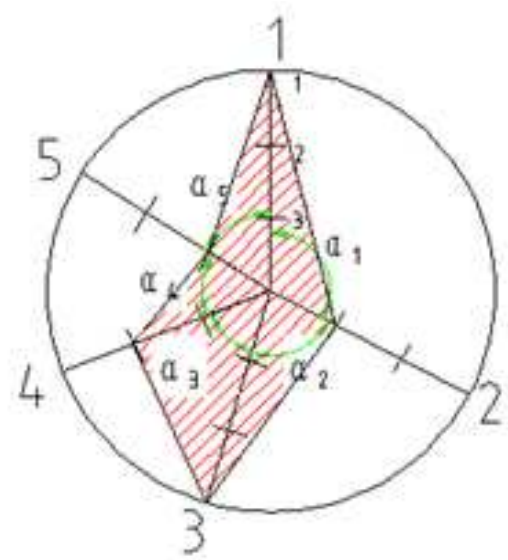

Fig. 4: Performance evaluation radar chart for KAMA A.

and power may contribute to increasing efficiency. 3) Fuel consumption and cultivation depth of KAMA A are good, so its performance improvement should be considered from the comprehensive view of cultivation width, cultivation efficiency and soil crushing rate to enhance the operational performance. 4) Performance of Little White Dragon A and B are good. Subsequent improvements can be obtained by decreasing fuel consumptions and enhancing operation efficiency. 5) The overall performance of Honda A and B are stable. 6) Both A and 


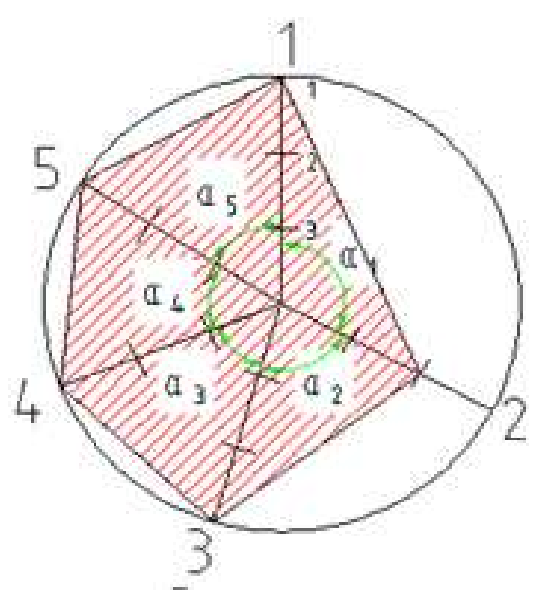

Fig. 5: Performance evaluation radar chart for KAMA model two.

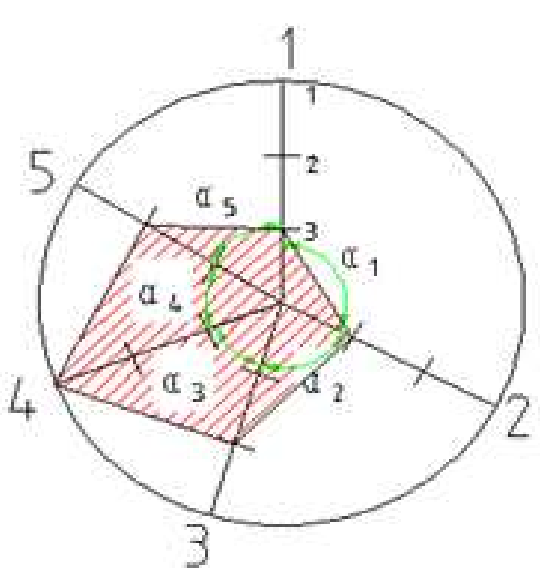

Fig. 6: Performance evaluation radar chart for Honda A.

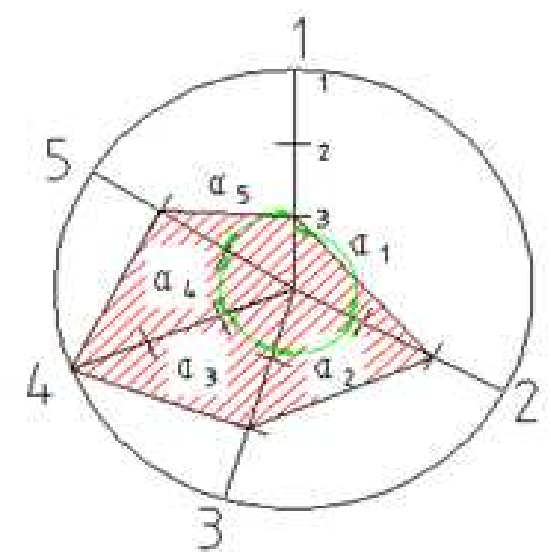

Fig. 7: Performance evaluation radar chart for Honda model two.

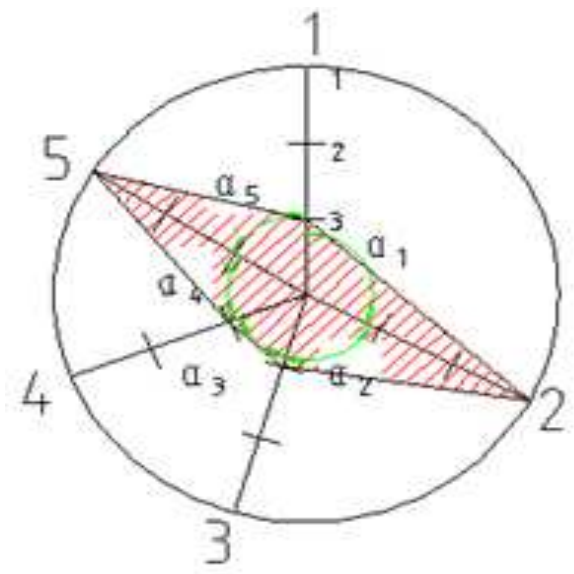

Fig. 8: Performance evaluation radar chart for TKK A.

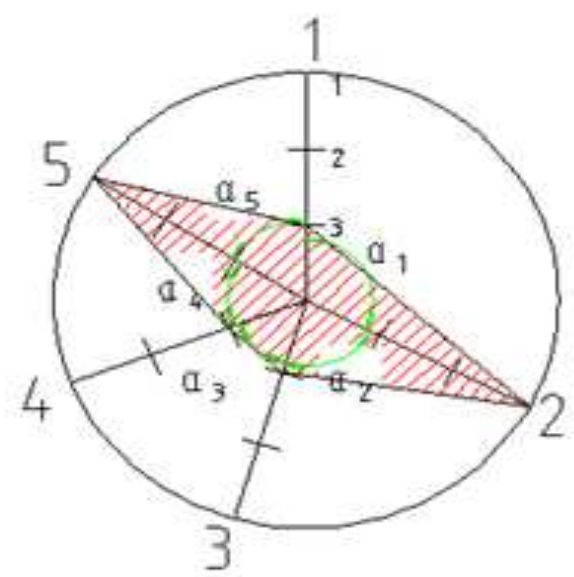

Fig. 9: Performance evaluation radar chart for TKK model two.

B of TKK operate with the same performance. The main problems of operations lie in high fuel consumption and poor cultivation effects. Subsequent improvements can be obtained by bettering their power transmission structure to enhance cultivation performance and diesel utilization.

\section{Acknowledgement}

This work was financially supported by Tea system of Industry \& Technology of Modern Agriculture of China (CARS - 23), Public Sector (Agriculture) Research of China (201303012) and Achievements Transformation Fund Program of Agricultural science and Technology of China (2012GB23260539).The supports are gratefully acknowledged. The authors would also acknowledge the Editor of Applied Mathematics \& Information Sciences. 


\section{References}

[1] Wang H, Xu R K, Wang N, et al. Soil acidification of alfisols as influenced by tea cultivation in Eastern China[J]. Pedosphere, 20, 799-806 (2010).

[2] Dan C, Guangwei R, Xiufang W, et al. Spray performance of four sprayers in the tea garden[J]. Plant Protection, 5, 025 (2011).

[3] Ye W, Tong Y, Li D, et al. Research on bridge cranes Energy-saving index reduction based on rough set theory [J]. TELKOMNIKA Indonesian Journal of Electrical Engineering, 11, 7269-7276 (2013).

[4] Tong Yifei, Ye Wei, Yang Zhen, et al. Research on Multidisciplinary Optimization Design of Bridge Crane [J]. Mathematical Problems in Engineering, 2013, 10 pages (2013).

[5] Yifei T, Yong H, Zhibing G, et al. Research on genetic algorithm-based rapid design optimization[J]. Mechanics, 18, 569-573 (2012).

[6] Chang Y C, Chang C J, Chen K T, et al. Radar chart: scanning for satisfactory QoE in QoS dimensions[J]. Network, IEEE, 26, 25-31 (2012).

[7] Paulrud S, Laitila T. Farmers attitudes about growing energy crops: a choice experiment approach[J]. Biomass and Bioenergy, 34, 1770-1779 (2010).

[8] TongYifei,Li Dongbo,Yu Minjian,etal. Research on multiattribute fuzzy optimal selection based on information axiomand [J].China Mechanical Engeneering, 18, 2029-2032 (2007).

[9] LI Yuanyuan, Yun Jun. Indicator system optimization and evaluation based on rough set[J]. Journal of Zhejiang University(Science Edition), 37, 411414 (2010)

[10] Wang Hongkai, Yao Bingxue, Hu Haiqing. The Method of Ascertaining Weight Based on Rough Sets Theory[J]. Computer Engineering and Applications, 36, 2021 (2003).

[11] Mustafa H I, Kozae A M, Lin T Y. Bi operation and rough sets generalizations[J]. Applied Mathematics \& Information Sciences, 2, 1-19 (2008).

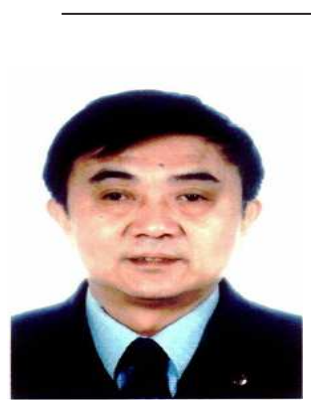
Ministry of Agriculture.

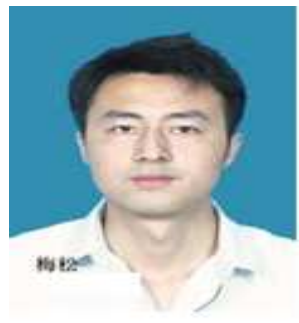

engineering machinery.

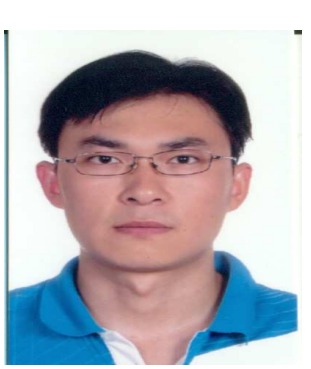

Song Zhiyu received the masters degree in Anhui Agricultural University. And now he is a Research Assistant at Nanjing Research Institute for Agriculture Mechanization Ministry of Agriculture. His research interests are in areas of tea mechanization.

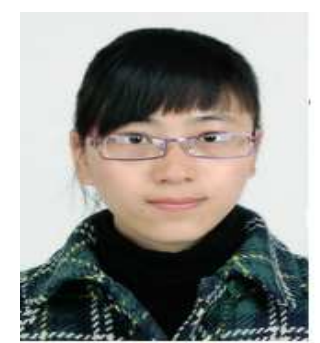

Ding Wenqin received the masters degree in Jiangsu University.She is an Research Assistant at Nanjing Research Institute for Agricultural Mechanization Ministry. Her research interests are in areas of Mechanical design and theory.

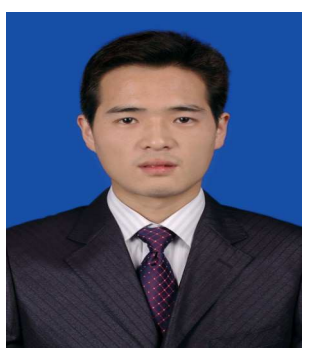

agricultural and engineering science.
Han Yu received the masters degree in Agricultural Mechanization Engineering at Chinese Science. His research interests are in areas of agricultural mechanization and automation. $\mathrm{He}$ has published research articles in reputed journals of Academy of Agricultural 